\title{
Advances in the monitoring of geo-structure subjected to climate loading
}

\author{
Alessandro Tarantino ${ }^{1, a}$, Domenico Gallipoli ${ }^{2}$, Cristina Jommi ${ }^{3}$, Joao Mendes $^{2}$, Anastasia Capotosto ${ }^{1}$, Alessia Amabile $^{1}$, \\ Matteo Pedrotti ${ }^{1}$, Annarita Pozzato ${ }^{1}$, Vojtěch Beneš ${ }^{4}$, and Fabio Bottaro ${ }^{5}$, Heiner Denzer ${ }^{6}$, and Fabian Boeck ${ }^{7}$ \\ ${ }^{1}$ University of Strathclyde, Department of Civil and Environmental Engineering, G11XJ Glasgow, UK \\ ${ }^{2}$ Laboratoire SIAME, Equipe Géomatériaux et Structures du Génie Civil, Université de Pau et des Pays de l'Adour, 64600 Anglet, France \\ ${ }^{3}$ Department of Geoscience \& Engineering, Delft University of Technology, 2600 GA Delft, Netherlands \\ ${ }^{4} \mathrm{G}$ Impuls Praha, 17000 Praha 7-Holešovice, Czech Republic \\ ${ }^{5}$ Tecnopenta srl, 35037 Teolo (PD), Italy \\ ${ }^{6}$ Pessl Instruments GmbH, Weiz, 8160 Austria \\ ${ }^{7}$ UMS GmbH, 81379 Munich, Germany
}

\begin{abstract}
The paper presents results achieved within the project MAGIC, a project funded by the European Commission under the Marie-Curie Industry Academia Partnerships and Pathways (IAPP) scheme. The project MAGIC aims to advance the state-of-the art in the monitoring of geo-structures subjected to climate loading by filling some of the gaps in current monitoring technologies. The project involves a partnership between academic and industrial partners to boost knowledge transfer and promote the development of 'industrial' instruments and services. The paper presents developments concerning the measurement of pore-water tension (suction in excess of $100 \mathrm{kPa}$ ) and the integration of geotechnical and geophysical monitoring.
\end{abstract}

\section{Introduction}

Major geotechnical infrastructure (road and railway embankments, dams, flood embankments, excavations, cut slopes) and natural geo-structures such a slopes are exposed to the atmosphere and are strongly affected by climate loading. Monitoring systems are crucial to assess climate hazard to geo-structures, minimise climate vulnerability via early-warning systems, and devise adaptation measures to enhance climate-resilience.

The literature is rich of research contributions documenting approaches to geo-structure monitoring. However, there appears to be a gap in industrial geotechnical monitoring. Companies provide a wide range of traditional instruments and monitoring services but are generally unprepared to devise solutions for climate interaction monitoring.

The project MAGIC 'Monitoring systems to Assess Geotechnical Infrastructure subjected to Climatic hazards', funded by the European Commission under the Marie-Curie Industry-Academia Partnerships and Pathways (IAPP) scheme aims to address this gap. It involves three academic and four industrial partners:

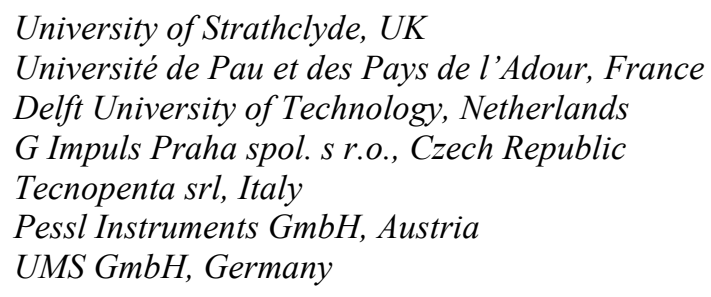

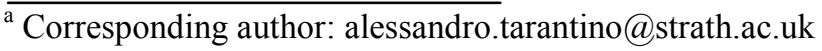

Systems for monitoring the ground-atmosphere interaction are routinely devised for agricultural applications. These include most of the sensors that are required for geotechnical installations and can therefore serve as a basis for industrial geotechnical monitoring systems. The partner PESSL is indeed specialised in agricultural monitoring and brings into the project the experience in the installation and operation of sensors under a wide range of soil and climate conditions.

Systems based on local sensors pose two challenges, that is i) where to install the sensors to ensure that the local measurement is representative of the ground/geostructure as a whole and ii) how to extrapolate the spatial distribution of the variables measured locally. Systems based on local sensors also suffer from another limitation, they are difficult to implement for the case where geotechnical hazard has to be assessed at the regional scale (e.g. flood embankments and shallow landslides at the catchment scale). These issues can be addressed successfully by integrating the geotechnical monitoring with the electrical geophysical monitoring. Preliminary geophysical investigation can be of great help to characterise the geo-structure and optimise location of 'geotechnical' sensors. At the same time, electrical geophysical 'diffuse' monitoring allows mapping the spatial distribution of electrical resistivity and, hence, of water content, which can integrate the more accurate information acquired from local sensors. The partner GIMPULS makes available this expertise to the project.

Sensors currently included in agricultural installations cover most the requirement for geotechnical monitoring 
with one exception, the measurement of pore-water tension (suction). Conventional tensiometers only cover the range $0-80 \mathrm{kPa}$, which is generally exceeded during the summer period. Sensors for indirect measurement of suction based on the measurement of electrical or thermal properties of a porous element in contact with the soil are generally suitable for agricultural but not for geotechnical applications. These sensors suffer from slow response and poor accuracy in the low suction range and are therefore not suitable for capturing rapid changes in suction associated with rainwater infiltration or propagation of a water front. High capacity tensiometers (HCT) can potentially address this gap. However, no HCTs are available commercially to date. MAGIC has therefore involved two companies, UMS and TECNOPENTA, to address the problem of shallow and deep measurement of pore-water tension respectively.

The paper therefore presents some of the advances made in the development of instruments for the direct measurement of suction in excess of $100 \mathrm{kPa}$ and the integration of geophysical monitoring with geotechnical monitoring.

\section{Shallow measurement of pore-water tension}

The high-capacity tensiometer (HCT) for pore-water tension measurement was invented in the early 90's by Ridley and Burland [1]. Since then, a number of prototypes have been developed essentially for research purposes as documented by [2], [3], and [4] with the most recent HCT presented by Mendes and Buzzi in 2013 [5].

Despite a large number of examples of successful measurement of pore-water tension in the laboratory, there are essentially no 'industrial' HCT tensiometers available on the market. This is likely due to the nonconventional design of HCT, the relatively complex experimental procedures required for tensiometer conditioning (including its first saturation), and the relatively limited evidence of HCT successful performance in the field.

This section presents a number of studies aimed at simplifying HCT design and conditioning procedures in order to make HCT more suitable for industrial applications. This study involves cooperation between the Université de Pau et des Pays de l'Adour (UPPA), UMS $\mathrm{GmbH}$, the University of Strathclyde, and PESSL Instruments.

\subsection{Design concept}

Two main design concepts have been put forward over the years, integral-strain gauge diaphragm tensiometers and 'assembled' tensiometers, i.e. tensiometers obtained by fitting a High Air-Entry Value (HAEV) ceramic disk onto a commercial transducer.

The advantage of integral-strain gauged diaphragms is that connections and, hence, potential entrapment of cavitation nuclei are minimised. However, integral-strain gauged diaphragms are home-made and they may therefore suffer from relatively poor repeatability and are relatively expensive not being mass-produced. In addition, they tend to be temperature sensitive and this makes them suitable for laboratory but not field use.

For industrial applications, the 'assembled' design might be a much more convenient choice. Mendes et al. [6] have investigated the performance of assembled tensiometers based on ceramic flush diaphragm, ceramic cavity diaphragm, and stainless steel flush diaphragm transducers (UPPA HCT design). The performance of all these prototypes appeared to be satisfactory in terms of maximum sustainable tension and comparable to the performance of HCT based on integral strain-gauged diaphragms. This is also consistent with the good performance of other epoxy-assembled transducers as discussed by Delage et al. [4].

Figure 1 shows the three UPPA prototypes based on ceramic pressure transducers. In prototype 4 , the HAEV ceramic filter was directly glued onto a ceramic cavity diaphragm transducer. The water reservoir was formed by the transducer cavity having a relatively large volume $\left(\sim 430 \mathrm{~mm}^{3}\right)$ compared to the majority of HCT prototypes published in the literature. If the maximum sustainable tension is investigated by letting the ceramic filter dry (Figure 2), it can be observed that Prototype 4 exhibits a maximum sustainable tension of around $-1800 \mathrm{kPa}$, which is comparable to that of Prototypes 2 and 3 having a small water reservoir.

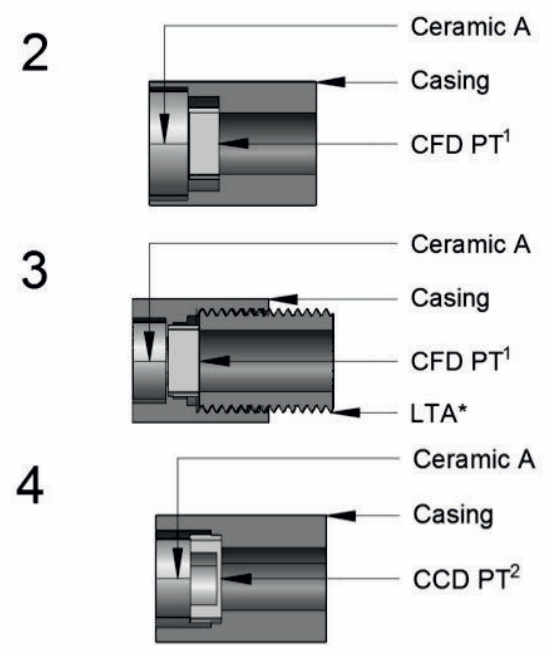

Figure 1. UPPA HCT prototypes based on ceramic sensors [6]

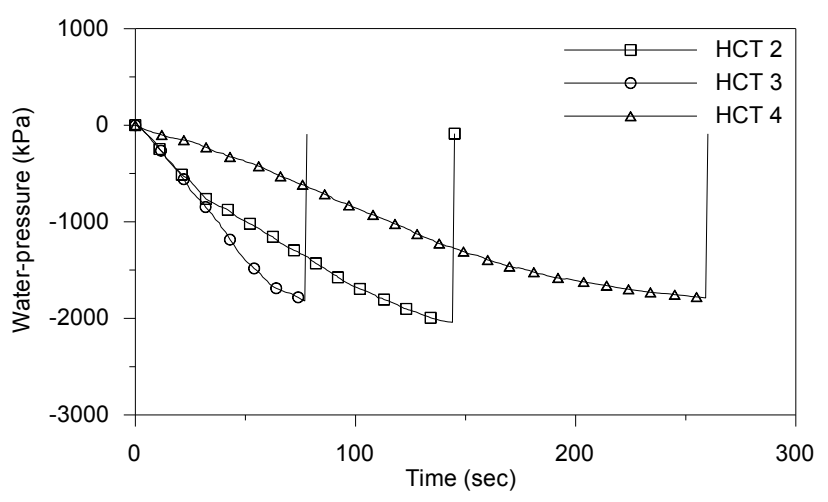

Figure 2. Response upon drying of UPPA tensiometers [6] 
It therefore appears that the reservoir size does not have a marked influence on measuring range. This is consistent with the findings of Mendes and Buzzi [5] and Tarantino and Mongioví [7] suggesting that cavitation initiates in the porous ceramic rather than in the reservoir.

Successful performance can then be achieved by mounting a HAEV ceramic onto a commercial pressure transducer and that there is apparently no need to push the size of the water reservoir to very small values (i.e. advanced machining skills and technologies are not required).

\subsection{Conditioning and periodical re-saturation}

Initial saturation of the porous ceramic has always been considered a critical step to ensure adequate performance of HCT. Procedures have become more and more sophisticated, involving preliminary removal of adsorbed water via pre-heating or silica gel adsorption, ceramic evacuation in the absence of water to maximise vacuum, and ceramic flooding under vacuum [3]. These procedures are difficult to implement in an industrial laboratory. In addition, accidental desaturation in the field is an event that should be considered in industrial practice. If this happens, it will be very unpractical (and unacceptably time-consuming) sending the HCT back to the manufacturer for reinitiating the initial saturation procedure.

The procedure based on the 'one-shot' initial saturation was therefore investigated by Pedrotti et al. [8] using a tensiometer similar in design to [9]. An air-dried HCT was placed in the saturation chamber and then almost immediately pressurised to $4 \mathrm{MPa}$. The response of the tensiometer during the first hour of the 'one-shot' saturation is shown in Figure 3. It took around $8 \mathrm{~min}$ (from $t=2 \mathrm{~min}$ to $t=10 \mathrm{~min}$ ) for the tensiometer to record the external pressure applied. This time lag is clearly associated with the ingress of water into the porous ceramic.

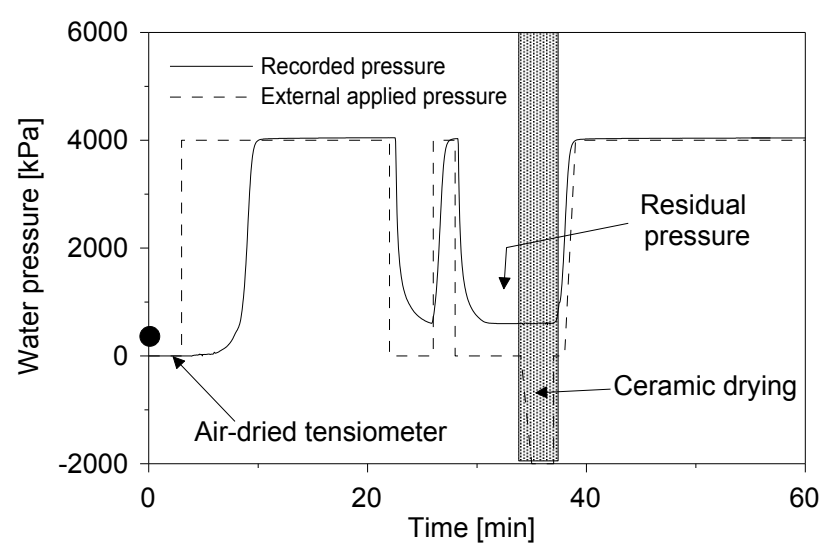

Figure 3. Pressurization-depressurization cycles within the first hour of one-shot saturation (Pedrotti et al. [3]).

The pressure in the saturation chamber was then cycled twice between $4 \mathrm{MPa}$ and $0 \mathrm{MPa}$ (from $t=21 \mathrm{~min}$ to $t=34 \mathrm{~min})$. When releasing the external pressure, a significant residual pressure of about $600 \mathrm{kPa}$ remained 'locked' in the tensiometer. The unbalance between the external water pressure and the water pressure in the tensiometer reservoir is likely carried by the menisci present in the unsaturated ceramic filter. This unbalance, although associated with an extreme condition, is clear evidence that the (negative) water pressure in the tensiometer water reservoir may differ from the 'external' water pressure applied on the outer side of the ceramic filter. Before re-applying a positive pressure, an attempt was made to generate water tension in the tensiometer by exposing the porous ceramic to air-drying (from $t=35 \mathrm{~min}$ to $t=37 \mathrm{~min})$. However, no water tension could be recorded.

After the first hour, a constant external pressure of 4MPa was applied to the HCT. During the subsequent 8day period, this external pressure was periodically released to zero for a few minutes only. Upon each pressure release, the residual excess pore water pressure was recorded. Figure 4 shows the residual excess water pressure versus the time elapsed from the first saturation. The residual excess water pressure recorded upon pressure release attained $0 \mathrm{kPa}$ after 8 days of almost continuous 4MPa pressurization (circle in Figure 4). The absence of a residual excess water pressure was taken as an indicator of adequate saturation of the ceramic filter. By fitting the residual excess water pressure with an exponential function, a time of about 4 days can be estimated as the time required to achieve saturation of the ceramic filter in 'one-shot'.

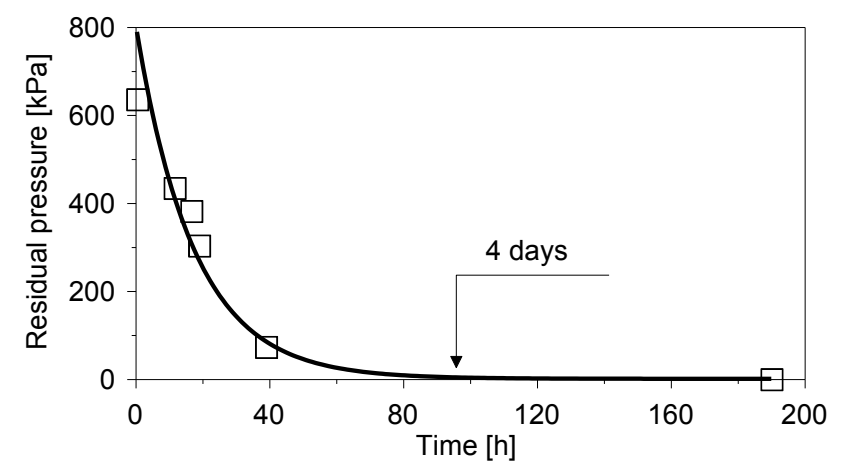

Figure 4. Residual pressure at atmospheric pressure after pressurization (Pedrotti et al. [3])

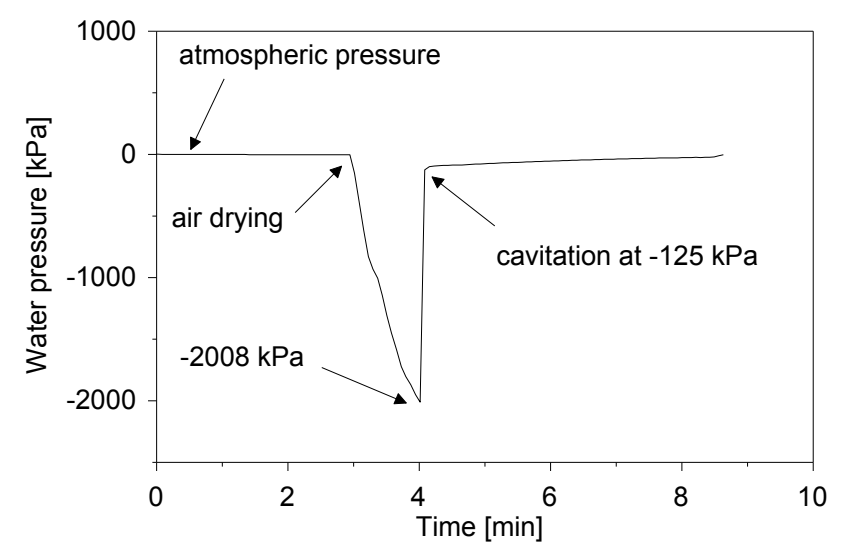

Figure 5. Air-drying cavitation (after $\sim 8$ days of pressurisation) (Pedrotti et al. [3]). 
After 8 day pressurisation, the tensiometer was indeed able to sustain negative water pressures for the first time as Figure 5. Noticeably, the water pressure recorded was much higher than the nominal air-entry value of the porous ceramic $(1.5 \mathrm{MPa})$. This response is generally accepted as evidence of adequate saturation of the porous ceramic. Following the results shown in Figure 5, new tensiometers have been saturated in one-shot. The performance of other tensiometers saturated using the 'one-shot' procedure is discussed in section 3 .

\subsection{Laboratory and field performance}

Although Toll et al. [10] and Cui et al [11] have presented successful examples of field measurement, evidence of field performance of HCTs still remains scarce. Within the project MAGIC, field measurements are planned in two sites in France and one site in Scotland.

The layout of the station installed in Orist (France) by UPPA and PESSL is shown in Figure 6. It includes a weather station (rain gauge, and sensors for air humidity and temperature, solar radiation, and wind speed), the tensiometer developed at UPPA similar to Prototype 3 in Figure 1 (MAGIC tensiometer), two water content sensors (ERC-5 by Decagon), one porous ceramic suction sensor (MPS6 by Decagon), and one temperature sensor (combined with the MPS6)

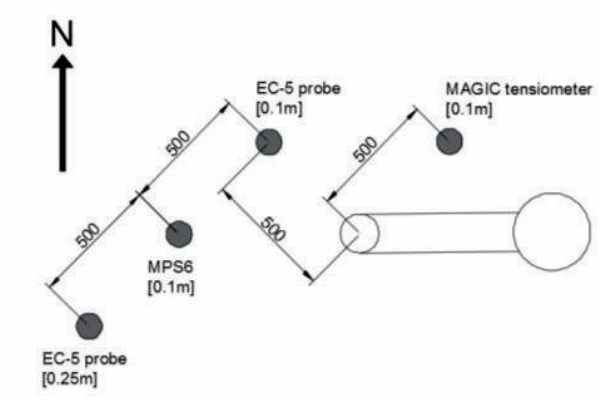

Figure 6. Layout of the system at Orist - Landes (France). EC-5 $=$ capacitive water content sensor, MPS $6=$ porous ceramic suction sensor, MAGIC $=$ high-capacity tensiometer.

The response of the instruments over 1 month is shown in Figure 7. The MAGIC tensiometer and the water content sensor are subjected to significant daily fluctuations associated with soil temperature changes (sensors were installed very close to ground surface where ground temperature is significantly affected by the daily fluctuation of air temperature).

To remove the effect of daily fluctuation, data were first smoothed by running average. With this correction, the output from the MAGIC tensiometer (thin black curve in Figure 7) still appears to be in phase with the temperature and not very consistent with the changes in water content during the initial dry period (until about $1 / 1 / 2016)$.

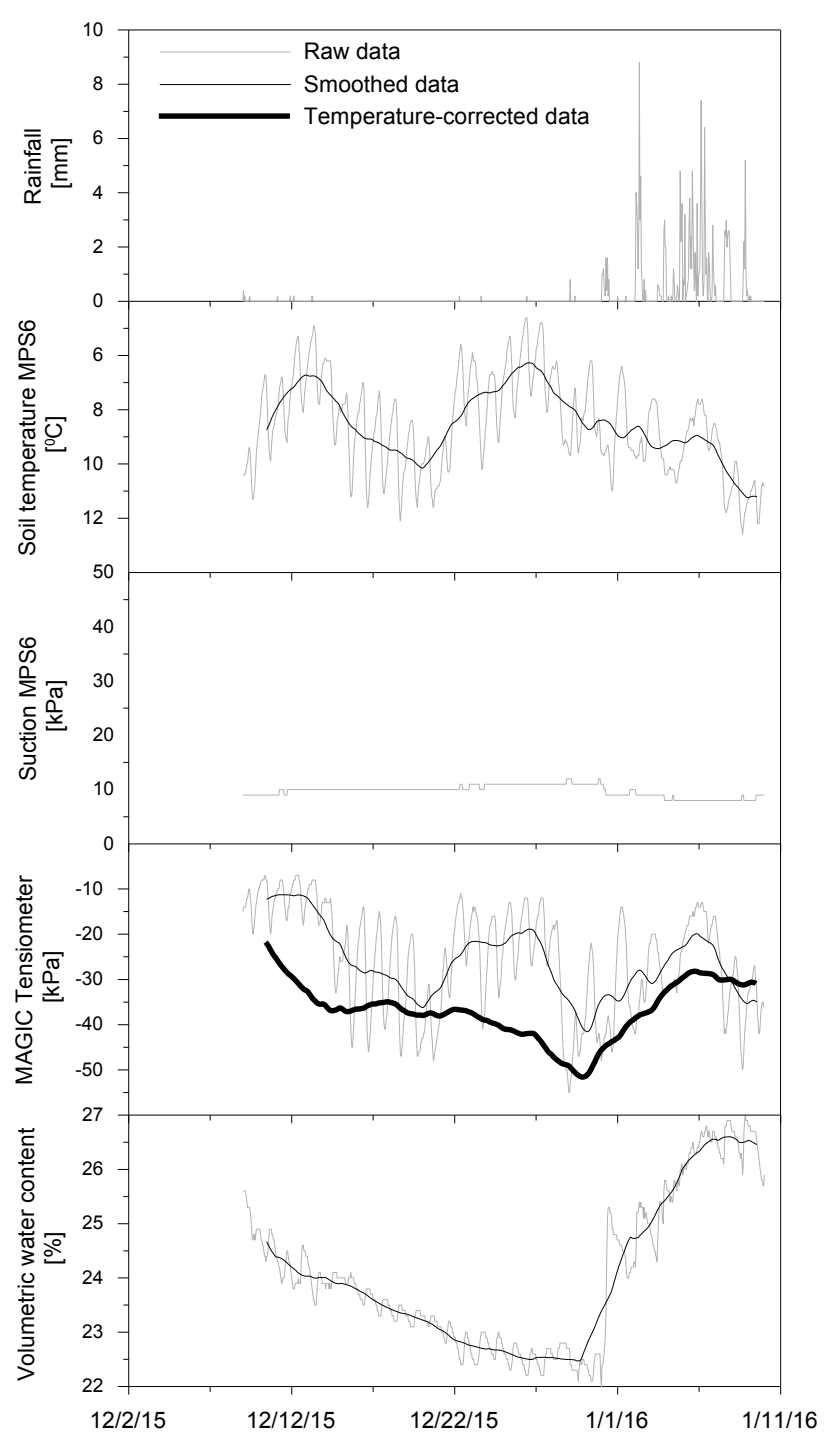

Figure 7. Response of the MAGIC HCT in the field and comparison with other sensors

The temperature effect on MAGIC tensiometer response clearly appears when the MAGIC tensiometer pore-water pressure is plotted against soil temperature (Figure 8). If the MAGIC tensiometer data are corrected using the linear regression in Figure 8 , the pore-water pressure (thick black curve Figure 7) now appears to be consistent with the water content data. In fact, during the rainfall event started on $1 / 1 / 2016$, both pore-water pressure and water content increase.

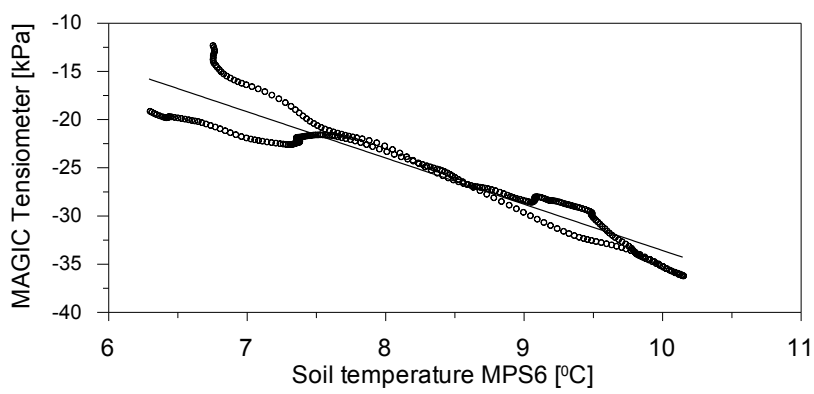

Figure 8. Correlation between MAGIC tensiometer response and soil temperature. 
The response of the MAGIC tensiometer therefore appears to be satisfactory if temperature effects are corrected for. This MAGIC tensiometer has been measuring suction uninterruptedly for almost 8 months to date (from August 2015 to March 2016) with peaks in suction reaching about $200 \mathrm{kPa}$ during the summer period. This appears to be one of the longest field measurement performance recorded for a HCT.

Concerning the temperature sensitivity of the MAGIC tensiometer, it is worth noticing that the ceramic pressure sensor itself was temperature-compensated and its sensitivity, measured in the laboratory before installing it in the tensiometer casing, only resulted in $0.16 \mathrm{kPa}{ }^{0} \mathrm{C}$. The higher temperature sensitivity shown by the tensiometer in the field is therefore likely due to differential thermal deformation of the pressure transducer and the casing. These should be eliminated in future tensiometer designs.

Finally, it is worth noticing that the suction sensor MPS6 (see Figure 7) dod not respond to changes in water content presumably because suction is very close to the limit of the measurement range.

\section{Deep measurement of pore-water tension}

High-capacity tensiometers (including the one developed within the MAGIC project) are suitable for shallow installations. However, if suction needs to be measured at depths greater than say $1 \mathrm{~m}$, the installation becomes problematic. One option is to drill a borehole and install the HCT at its bottom. However, the contact might be difficult to ensure and a closure should be devised that allows removal of the tensiometer while preventing soil water evaporation during measurement. Another option is the probe locator presented by Toll et al. [10] consisting of a $3 \mathrm{~m}$ long PVC cylinder buried into the ground. Openings at various depths on the sides of the probe locator allow the HCTs to be installed in contact with the ground (HCTs are slid down through appropriate guides). However, this installation is relatively costly and complex to implement and it is unlikely that this system is adopted commercially at this stage.

The option pursued by the MAGIC project is to install the HCT on a penetrometer shaft having the same size and connections of a CPT shaft. In this way, the HCT can be pushed down into the ground using the very common CPT push system. This work results form cooperation between the University of Strathclyde and Tecnpoenta srl.

\subsection{HCT for the deep installation}

The HCT mounted on the penetrometer shaft is shown in Figure 9. It is similar in concept to the one developed by [9] with its size reduced to accommodate it into the $36 \mathrm{~mm}$ diameter penetrometer shaft.

The HCT was saturated using the one-shot procedure. The response of two penetrometer HCTs after 5-day pressurisation at $4 \mathrm{MPa}$ is shown in Figure 10. They could both measure pore-water tension successfully with cavitation occurring at around $800 \mathrm{kPa}$, which is the airentry value of the porous ceramic used.

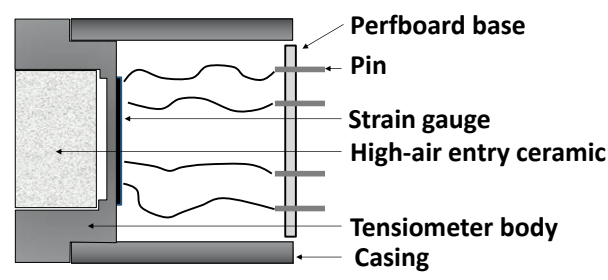

Figure 9. HCT mounted on the penetrometer shaft.

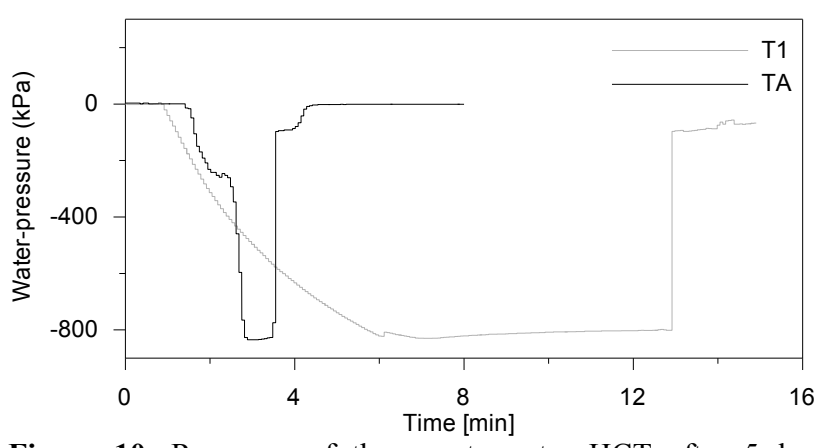

Figure 10. Response of the penetrometer HCT after 5-day pressurisation at $4 \mathrm{MPa}$.

To test their response, these two penetrometer HCTs were simultaneously installed on a clay sample using the suction measurement box shown in [9]. The HCTs were installed just after the 5-day one-shot pressurisation and another 5-day pressurisation at $4 \mathrm{MPa}$ following the cavitation test shown in Figure 10.

The aim of this test was to assess the performance of the two HCTs. They were installed in pair as this is the only way to ensure that pore-water tension measurement is reliable. As shown in Figure 3, the pressure measured by the tensiometer may differ from the external porewater pressure if menisci are present in the ceramic filter. However, if the two HCTs are measuring the same porewater tension, this is the best evidence that pore-water tension is measured reliably. It is extremely unlikely that random meniscus configuration in the two HCTs are leading to the same 'false' water tension in the water reservoir of the two tensiometers.

The measurement is presented in Figure 11. It shows fluctuation in suction due to water drops condensing on the lid of the box and dripping on the sample.

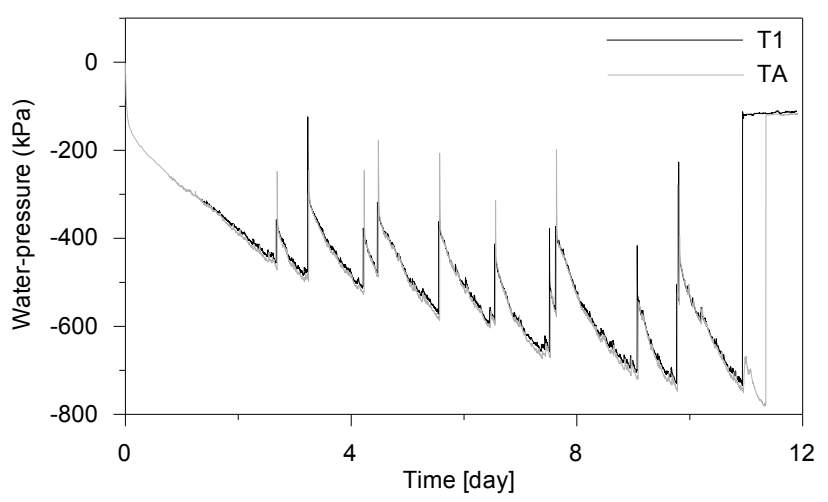

Figure 11. Long-term measurement using two penetrometer HCTs. 
The two HCTs were successfully measuring the same pore-water tension despite the fluctuations due to water dripping. This result is noteworthy as the two HCTs were saturated using the one-shot procedure. Measurement duration is also remarkable ( 11 days), with cavitation occurring only because the $800 \mathrm{kPa}$ air-entry value of the ceramic filter was approached.

\subsection{Prototype penetrometer shaft and laboratory measurements}

The prototype penetrometer shaft carrying the HCT is shown in Figure 12. The main issue in the measurement of pore-water tension in this configuration is the contact between the tensiometer ceramic filter and the soil. In surface installations, a soil paste is usually interposed between the tensiometer ceramic filter and the soil [12]. A paste cannot be applied onto the penetrometer HCT and contact can only be ensured by the radial compression of the soil surrounding the penetrometer shaft during penetration.

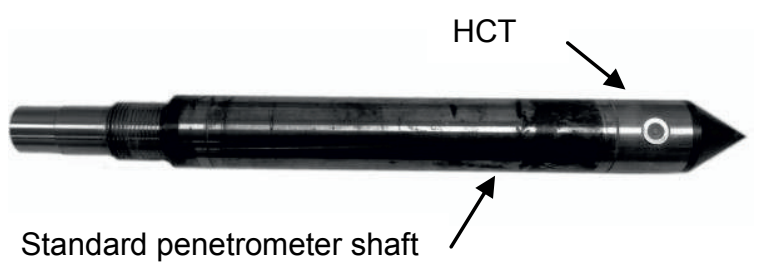

Figure 12. Prototype penetrometer shaft

To test whether adequate contact can be established during penetration, the penetrometer was installed through a soil sample contained into a $100 \mathrm{~mm}$ diameter and $150 \mathrm{~mm}$ height mould as shown in Figure 13. A HCT was installed at the top of the sample (through the confining lid) to double check the measurement of the penetrometer HCT.

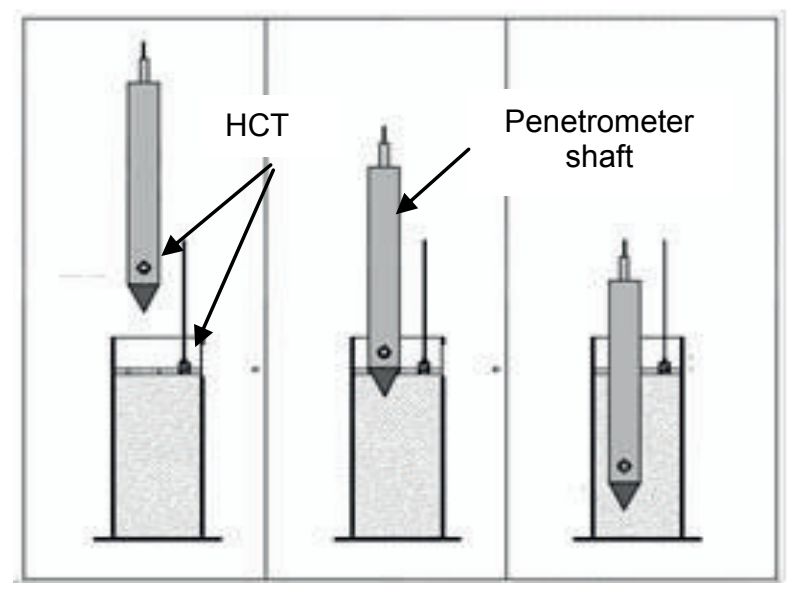

Figure 13. Mock-up scale test to simulate measurement during penetration.

The result on a test performed on a lightly compacted sample prepared with $80 \%$ Sand and 20\% Kaolin ( $w=40 \%$ with respect to the kaolin mass) is shown in Figure 14.
The pore-water pressure measured by the penetrometer HCT decreased during penetration and then increased to an equilibrium value after the shaft penetration was stopped. The top HCT initially recorded an over pressure (due to the soil compression associated with the shaft penetration) and then levelled off to the same value recorded by the penetrometer HCT. This test shows that contact could be established even under unfavourable conditions. In fact, the soils included a high fraction of course-grained material (this makes the contact more difficult to achieve) and the soil was lightly compacted (low radial stresses develops during penetration because of the low density).

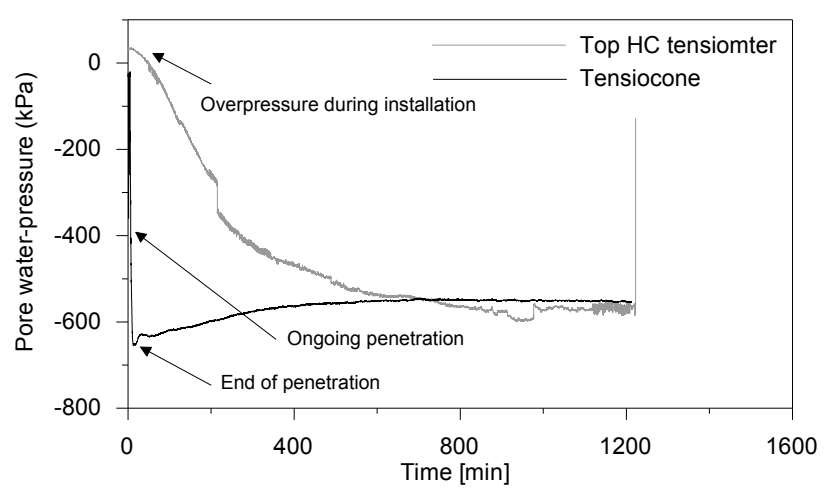

Figure 14. Penetration test in the laboratory

\subsection{Field test}

Following the tests in the laboratory, a test was carried out in the field. The penetrometer HCT was installed from the crest of a flood embankment with the phreatic surface located at around $7 \mathrm{~m}$ below the crest. The HCT was therefor expected to measure suction in the range 0 $70 \mathrm{kPa}$ as the pore-water pressure is essentially hydrostatic below the asphalt-covered embankment crest. The results of the field test are shown in Figure 15.

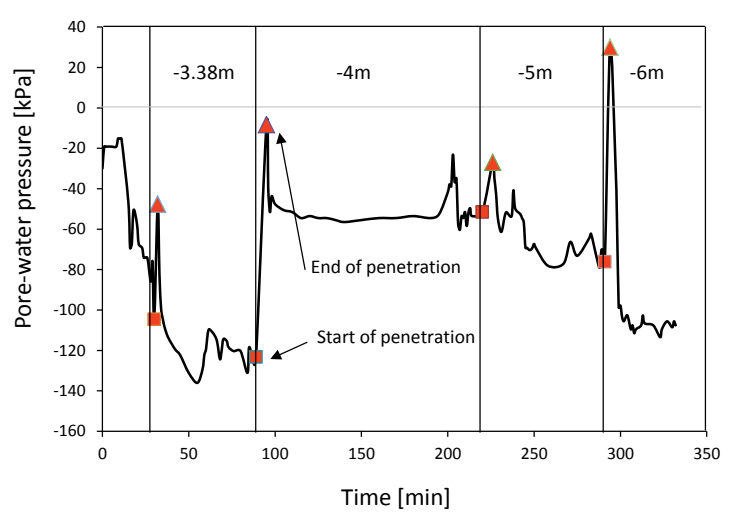

Figure 15. Field test of the penetrometer HCT

It can be observed that equilibrium could be reached after stopping the penetration, indicating that adequate contact could be established between the penetrometer $\mathrm{HCT}$ and the ground. However, the pore-water pressure readings were not consistent with a hydrostatic profile and not consistent with the values of suction established by the $7 \mathrm{~m}$ deep phreatic surface. 
Following these results, possible mechanical effects on pressure reading were inspected in the laboratory. The penetrometer was subjected to an axial load while keeping the penetrometer HCT at zero pressure (by covering the ceramic filter with wet cotton). It can be observed that spurious readings are significant. The compression of the shaft induces deformation in the HCT resulting in false pressure readings. This explains the almost random values recorded during the field penetration test. The major challenge in the design of the penetrometer shaft would therefore be isolating mechanically the HCT from the shaft and this will be addressed in future design of the penetrometer shaft.

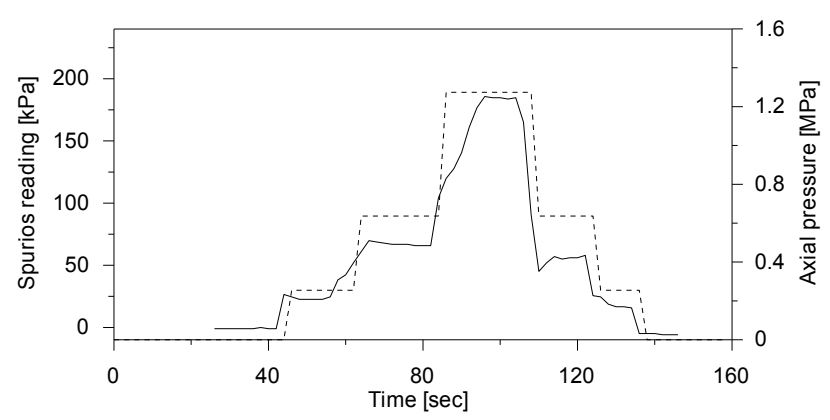

Figure 16. Mechanical effects on HCT tensiometer signal

\section{Geophysical monitoring}

Geophysical electrical methods can be used to monitor the water regime in geo-structures. Three methods were explored in the MAGIC project, the Electrical Resistivity Tomography (ERT), the Ground Penetrating Radar (GPR), and Slingram electromagnetic method (EM).

The ERT allows mapping the electrical resistivity of the ground. Above the groundwater table, the electrical resistivity is directly associated with the soil (volumetric) water content and the ERT therefore allows mapping the water regime in the vadose zone. The ERT is a relatively time-consuming technique compared to other geophysical electrical methods as it requires the installation of electrodes at the ground surface and relatively large number of scans.

The GPR allows for faster scanning of geo-structures and, similarly to ERT, provides a 2-D mapping of the ground. However, interpretation of GPR data is much more complex than ERT and it generally allows for the detection the phreatic surface/ground water table only.

The advantage of ERT and GPR in geotechnical design is that that the mapping water flow is faster and cheaper than methods based on conventional geotechnical instrumentation built upon local sensors (piezometer cells, tensiometers, and water content sensors). This makes these techniques appealing especially for hazard analysis at the regional scale (e.g. flood embankments and shallow landslides).

The EM is also a fast-scanning method and returns a single apparent resistivity of the ground. Different penetration depths can be achieved by varying either the distance between the transmitter and receiver coils or the frequency of the oscillating primary field.
The EM is the cheapest, fastest, and easiest-to-process monitoring technique and this makes it very suitable to be used as an early warning of flood embankments impending breach, provided suitable procedures are developed to interpret the resistivity data.

\subsection{Case studies}

Two case studies were considered to explore the potential of geophysical electrical techniques in geotechnical analysis. The first geo-structure is a flood embankment of the Adige River located in S. Florian in the province of Bolzano in Italy (Figure 17). A segment of the embankment was instrumented with piezometer cells to monitor the phreatic surface. The same segment was inspected using ERT, GPR, and EM.

The embankment is made of an inner core of silty sand and an outer 'shell' of sandy gravel (Figure 18). The embankment foundation consists of a sandy silt layer overlying a sandy gravel material. Samples were taken from the embankment core and the upper foundation layer to determine the relationship between electrical resistivity and volumetric water content and therefore allow converting ERT data into water content distribution.

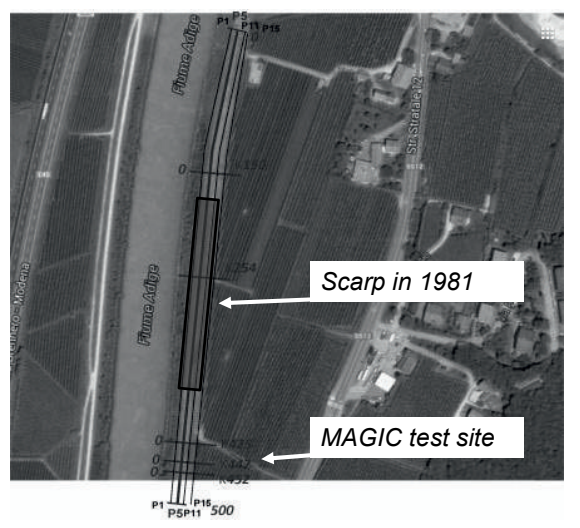

Figure 17. Adige river embankment in S.Florian, Italy

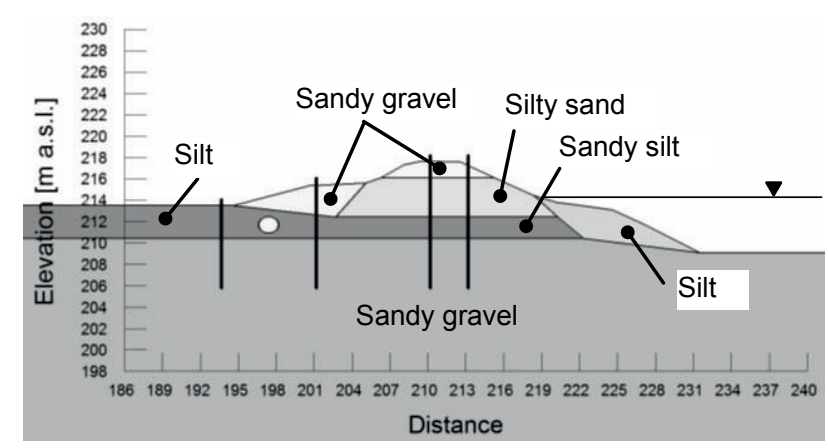

Figure 18. Cross section of the Adige river flood embankment

The second geo-structure is a flood embankment protecting the Leendert de Boerspolder, a small island (polder) in the Kagerplassen in the Netherlands. Flood embankments are made of clay (though mixed with recycled materials used when the water barrier was built well over 500 years ago) and are founded on peat bog. 
Water level is almost at the crest on the water side whereas it is about $50-100 \mathrm{~cm}$ below ground on the landside.

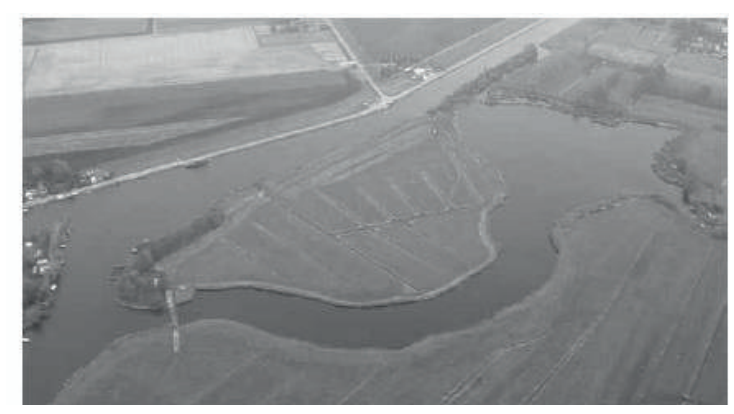

Figure 19. View of the Leendert de Boerspolder [13].

\subsection{Phreatic surface detection using GPR}

GPR measurement consists of high-frequency electromagnetic waves radiated into the investigated medium. If the investigated medium shows changes of dielectric permittivity properties, a portion of the wave is reflected back and registered by a receiving antenna. The travel time of the reflected wave, which is controlled by the dielectric permittivity of the medium, indicates the depth of the reflecting interface.

Fully digital dual-trace radar device SIR 20 (GSSI USA) was used for the measurements. Considering the expected depth of the investigated embankments, antennas of carrier frequency of 900,400 , and $100 \mathrm{MHz}$ were used. This frequency allows for penetration depth ranging between $1 \mathrm{~m}$ to $6-8 \mathrm{~m}$. The measurement was taken in a time window of 30-200 ns. Measured data have been processed with the RADAN 6.6 (GSSI - USA) program.

Figure 20 shows GPR reflection data from the Adige river embankment. The thick curve represents the blind prediction of the phreatic surface as inferred from high amplitude reflections. On the other hand, the dashed line represents the phreatic surface obtained from numerical simulation calibrated to the piezometer water level measured in the field. It can be observed that GPR estimation of the phreatic surface agrees reasonably well with the one inferred from local piezometer cells.

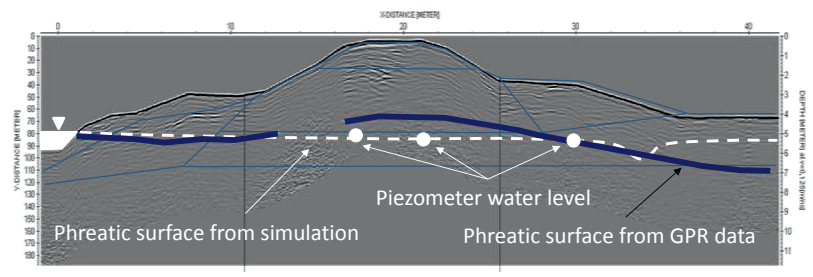

Figure 20.GPR data interpretation for the Adige river embankment, November 2014 (K452).

Figure 21 shows the GPR reflection data from the Leendert de Boerspolder embankment. Again, the thick curves represent the blind prediction of the phreatic surface as inferred from high amplitude reflections. Although no phreatic surface is simulated here, it can be observed that the prediction matches reasonably well the piezometer water level measured in the field on the land side and the water level on the left-hand water side (not shown in the figure), which is close to the embankment crest.

In summary, GPR appears to be able to detect the location of the phreatic surface in both fine-grained and coarse grained materials. It would be expected that the 'sampling' depth of GPR in clays is much lower than the one in granular materials due to dissipative attenuation occurring in clay. It is therefore likely that the phreatic surface down to about $6 \mathrm{~m}$ detected in the Adige river coarse-grained embankment could not have been detected if the embankment was made of clay.

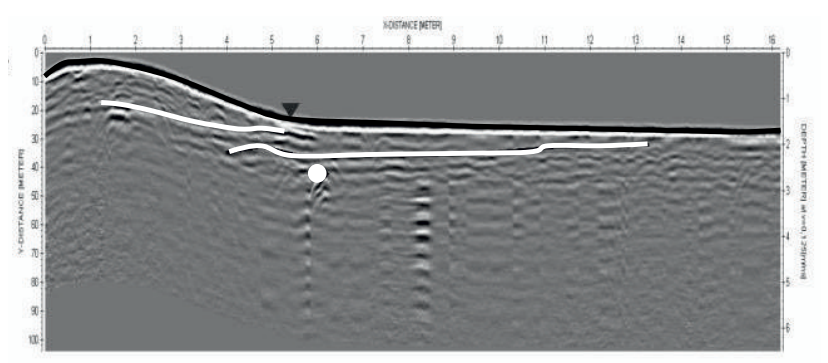

Figure 21. GPR data interpretation for the Leendert de Boerspolder embankment (K234)

\subsection{Water content mapping using ERT}

Electrical resistivity tomography (ERT) belongs to directcurrent geo-electrical resistivity methods. The principle of the method is based on the measurement of resistivity using a large number of electrodes in an array configuration. The electrodes are connected by a special cable that enables the current to be injected through a pair of electrode and the electrical potential to be red by the remaining electrodes in the array. A multiplexer sends the current to different pairs of electrodes through a set sequence. The distribution of electrical resistivity in the ground is obtained by tomographic reconstruction (inverse problem).

For the resistivity tomography measurement, the device ARES (GF Instruments, Czech Republic) has been used. 2-D resistivity sections were compiled using the programme Res2Dinv (GEOTOMO Software Malaysia). The ERT measurement was carried out using a Schlumberger electrode arrays and the results were processed using the $3^{\text {rd }}$ iteration of least squares method.

Figure 22 shows the ERT model for the Adige river embankment. The darker region at the top of the embankment close to the crest denotes higher resistivity do to the lower content in turn associated with the embankment pavement preventing infiltration of incident rainwater. High resistivity is also observed at the berm on the right-hand side (landside) due to the presence of a drainage system.

The ERT data were collected in three cross-sections along a $27 \mathrm{~m}$ long embankment segment in November 2014 (wet season) and June 2015 (dry season). Electrical resistivity data were then converted into volumetric water content using calibration curves developed in the laboratory on samples taken from the lower embankment and upper foundation. The ERT data were finally 
compared to the water content derived from the numerical simulation of water flow in turn 'calibrated' to field piezometer data.

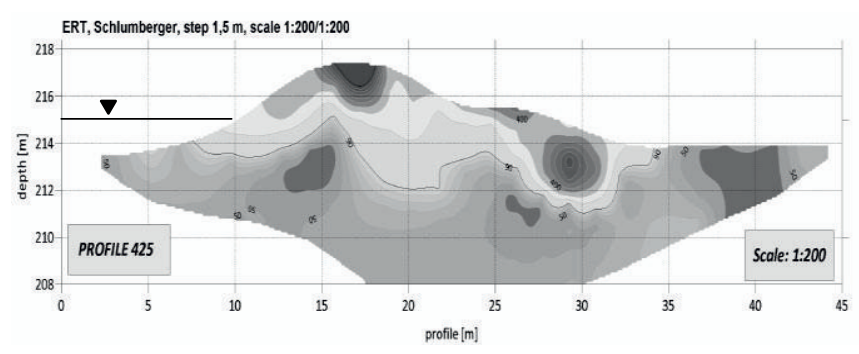

Figure 22. ERT data interpretation for the Adige river embankment, November 2014 (K425).

Figure 23 shows the performance of the ERT prediction against the data from the simulation for the November 2014 measurement. The agreement is very good for the water content in the upper and lower parts of the embankment. Prediction is less accurate in the saturated foundation layer. This can be attributed to the low sensitivity of the calibration curve at high water content and low resistivity.

Figure 24 shows the performance of the ERT prediction against the data from the simulation for the June 2015 measurement. The ERT simulation for the lower embankment is less accurate. The overestimation of the resistivity is likely associated with the drier upper layer that 'shadows' the inner core of the embankment. In fact, the ERT data in the lower embankment appears to become less accurate as the upper layer is approached. Further studies on the inversion method can probably eliminate this bias.

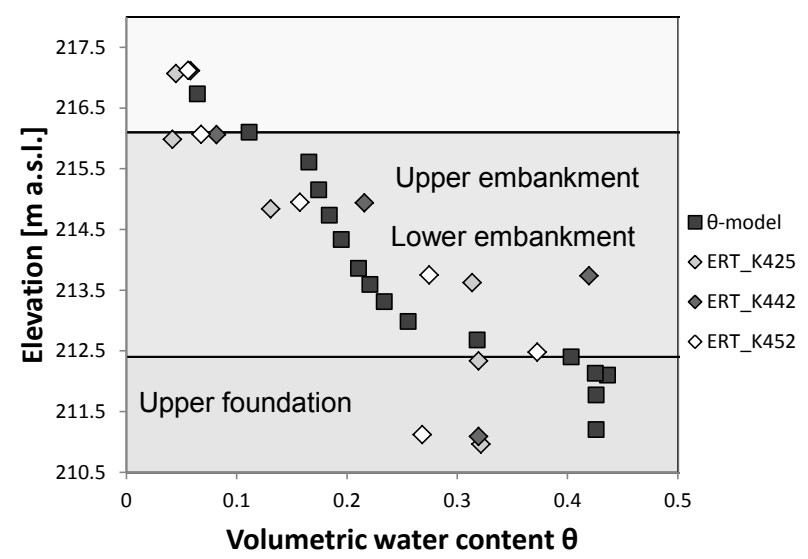

Figure 23. ERT data from Adige river embankment and comparison with simulated water content (November 2014).

Figure 25 show the ERT data from the Leendert de Boerspolder embankment. Contours of equal electrical resistivity close to the ground surface seem to follow the phreatic surface (water level on the left-hand side of the embankment is close to the crest and generates a rightward water flow). However, it would be difficult to locate the phreatic surface purely on ERT data. If the ERT data are integrated with the tentative location of the phreatic surface as inferred from GPR data (dashed curves), the phreatic surface can be located confidently as shown in Figure 25b.

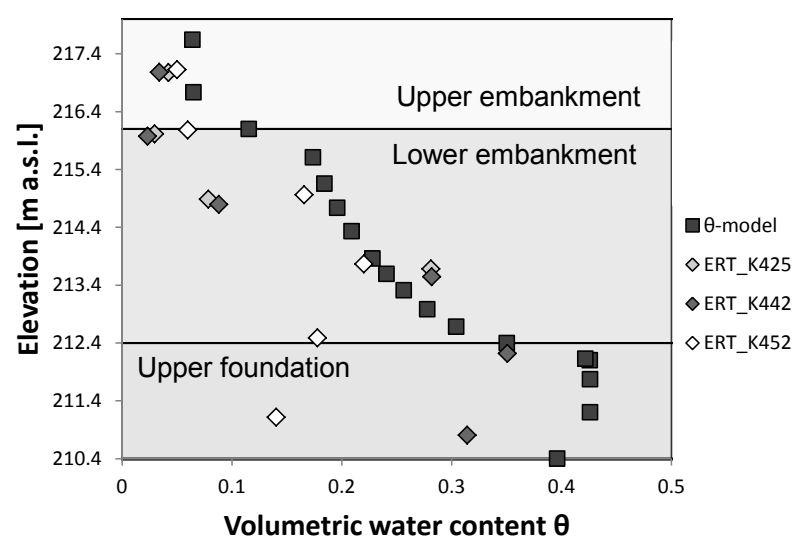

Figure 24. ERT data from Adige river embankment and comparison with simulated water content (June 2015).

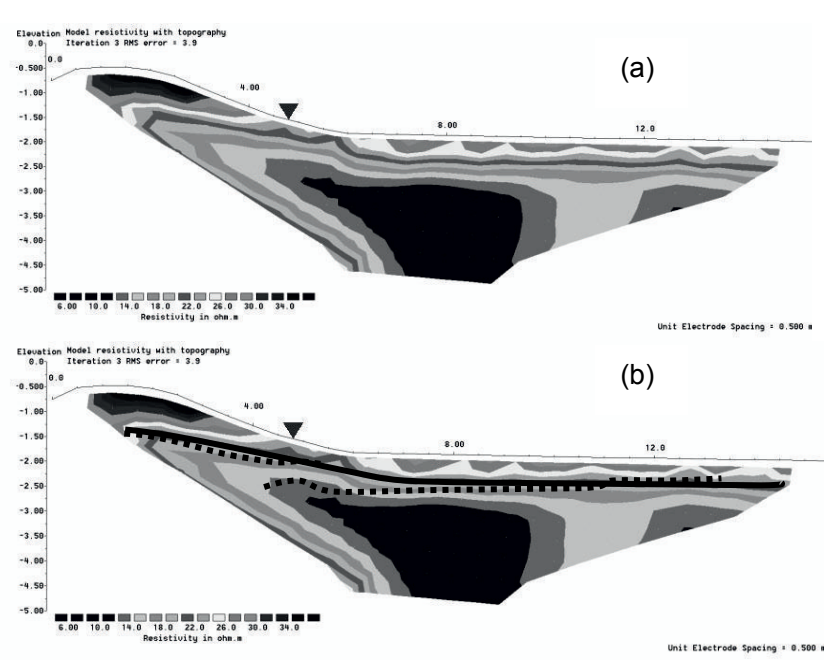

Figure 25. ERT data from the De Leendert de Boerspolder embankment. (a) Raw ERT data. (b) Phreatic surface drawn by integrating ERT and GPR data.

\subsection{Early-warning system based on Slingram electromagnetic method}

Slingram method consists of pair of moving transmitter and receiver coils. The oscillating primary field from the transmitter coil induces electrical currents in the subsurface that, in turn, generates a secondary magnetic field, which is picked up by the receiver coil. This secondary magnetic field is further divided into in-phase (real) and quadrature (imaginary) components, in turn dependent on the subsurface electrical conductivity.

In the project MAGIC, we used two types of equipment for multi depth EM profiling, the multifrequency sensor GEM2 (GEOPHEX, USA) and the multi-distance sensor CMD (GF Instruments, Czech Republic). Only data from the GEM2 are discussed herein.

Measurements were carried out by walking with the instrument over the embankment in cross diection (Figure 
26). The higher the distance between the ground surface and the phreatic surface, the higher will be the resistivity of the ground. Figure 27a shows the change in water depth when walking from the left-hand to the right-hand side of the embankment. Water depth is lower in November 2014 (wet season, high river level) than June 2015 (dry season, low river level)). The change in resistivity is shown in Figure $27 \mathrm{~b}$ and appears to be consistent with water depth. In this figure, raw resistivity data were smoothened and shifted to align the valleys in the water depth and resistivity profiles.

A correlation between equivalent electrical resistivity and water depth was established for the data from the June 2015 survey considering the portion of the crest dashed in Figure 26.

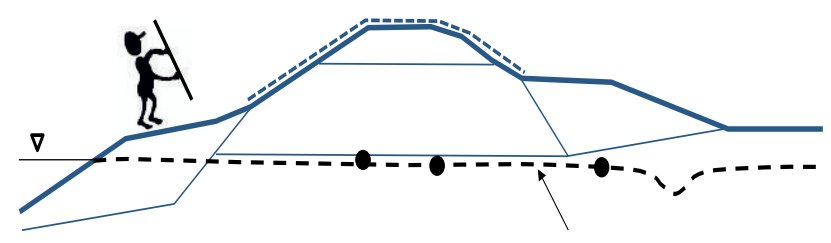

Phreatic surface

Figure 26. Inspection of the embankment cross-section using GEM2. The portion of the crest dashed indicates the segment where water depth was predicted based on GEM2 data.

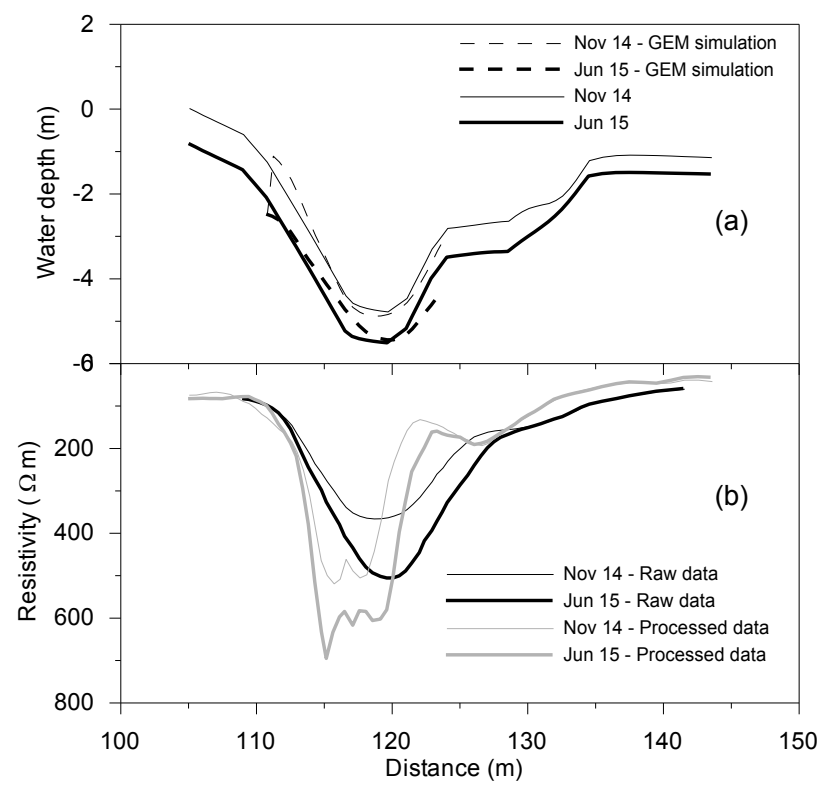

Figure 27. Electrical resistivity from EM profiling of the Adige River embankment associated with the November 2014 and June 2015 survey.

This correlation is shown in (Figure 28) and data were fitted using a straight line. Based on this correlation, the water depth profile was simulated from the EM resistivity data. The results of this simulation are shown in Figure 27a. The simulation of the June 2015 profile is obviously good as the correlation was indeed built upon the June 2015 data. On the other hand, the simulation of the November 2014 water depth profile should be regarded as prediction and it appears to reproduce fairly the field data.
In other words, if one was walking across the embankment in November 2015 during the wet season and was interpreting the electrical resistivity data based on the correlation developed for the June 2015 data (dry season), the raise of the phreatic surface in the embankment could have been properly detected. This shows the potential of the EM to be used as an indicator of water through-flow regime and, hence, of impeding breaching conditions.

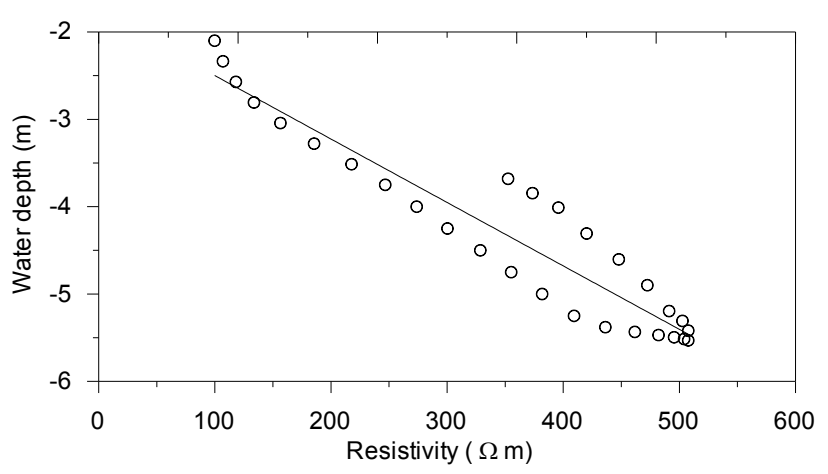

Figure 28. Calibration of GEM2 electrical resistivity against water depth (data relative to the June 2015 survey).

\section{Conclusions}

The paper has presented some advances in the monitoring of geo-structures exposed to climate loading with the aim of i) filling some of the gaps in current monitoring technologies and ii) developing 'industrial' instruments and approaches, i.e. ready to be implemented in routine geotechnical problems.

One of the gaps in 'industrial' monitoring technologies is the direct measurement of pore-water tension (suction in excess of $100 \mathrm{kPa}$ ) via high-capacity tensiometers. We have shown that tensiometer design and experimental procedures can be significantly simplified to facilitate the development of an 'industrial version of the HCT. 'Assembled' tensiometers, based on a high airentry ceramic fitted onto a commercial pressure transducer, are simpler to manufacture and have been shown to perform to the same standard as the integralstrain gauge tensiometers. Procedures for saturation can also be simplified as the one-shot saturation proved equally effective as procedures based on pre-evacuation of the ceramic filter.

We have also addressed the problem of deep measurement of pore-water tension by incorporating a HCT into a penetrometer shaft. Preliminary tests in the laboratory and in the field have demonstrated that adequate contact can be achieved between the soil and the ceramic filter even in absence of any interposed soil paste. Problems still remain to be solved concerning the mechanical effects on HCT response.

Electrical geophysical methods have also proven to be an extremely valuable tool to assess the water regime in geo-structures. GPR is capable of detecting phreatic surface/groundwater table in geo-structures in a faster and more economical way than traditional piezometer cells. If GPR is used in conjunction with traditional 
piezometer cells installed in strategic locations, significant time and financial saving can be made.

ERT allows for relative accurate mapping of water content if electrical conductivity versus volumetric water content can be assessed experimentally. Again, if used in conjunction with local sensors, this technique can allow identifying anomalies or discontinuities in the water flow regime that are impossible to detect using local sensors.

Finally, the EM technique can be potentially used as a system for early-warning of impending failure triggered by water flow. For example, this technique can complement visual inspection of operators patrolling flood embankments during the flood event.

\section{Acknowledgements}

We wish to thank all who have contributed to the work presented in this paper: Georg von Unold (UMS, Germany), Maura Bellio, Alice Pavanini, and Aurelio Busetto (Tecnopenta, Italy), Vlado Budinski (GImpuls Praha, Czech Republic), Gabriel Gomez (PESSL Instrument, Austria), Brunella Balzano and Arianna Pagano (University of Strathclyde), and Amin Askarinejad (TU Delft). We also wish to thank the Autonomous Province of Bolzano for making available data from the Adige River embankment. The financial contribution of the European Commission to this research through the Marie Curie Industry-Academia Partnership and Pathways Network MAGIC (Monitoring systems to Assess Geotechnical Infrastructure subjected to Climatic hazards) - PIAPP-GA-2012-324426 - is gratefully acknowledged.

\section{References}

Ridley and Burland [1] A.M. Ridley, and J.B. Burland. Géotechnique, 43(2): 321-324 (1993).

[2] A. Tarantino. Proc. 3rd Int. Conf. on Unsaturated Soils, Recife, Brasil, 3: 1005-1017 (2004).

[3] F.A.M. Marinho, A. Take and A. Tarantino. Geotechnical and Geological Engineering, 26(6): 615-631 (2008).

[4] P. Delage, E. Romero and \& A. Tarantino. Proc. 1st European Conference on Unsaturated Soils, Durham, UK: 33-52 (2008).

[5] J. Mendes and O. Buzzi, Can. Geotech. J. 50(5): 550-556 (2013).

[6] J. Mendes, D Gallipoli, F. Boeck, G. von Unold and A. Tarantino. E-UNSAT 2016, 3rd European Conference on Unsaturated Soils, Paris, France (2016).

[7] A. Tarantino and L. Mongioví. Geotechnical and Geological Engineering 19: 189-210 (2001).

[8] M. Pedrotti, F Boeck, and A. Tarantino. Proc. UNSAT 2014, Unsaturated Soils: Research \& Applications, Sydney, Australia: 1651-1657 (2016)

[9] A. Tarantino and L. Mongiovi. Geotechnique, 53: 137-41 (2003).

[10] D.G. Toll, S.D.N Lourenco, J. Mendes, D. Gallipoli, Evans, F.D., Augarde, C.E., Cui, Y.J., Tang, A.M., Rojas, J.C., Pagano, L., Mancuso, C., Zingariello, C., and A. Tarantino. Quarterly Journal of Engineering Geology and Hydrogeology, 44(1): 23-33 (2013).

[11] Y.J. Cui, A.M. Tang, A.T. Mantho and E. De Laure. Geotechnical Testing Journal 31 (1): 95-100 (2008).
[12] O.M. Oliveira and F.A.M Marinho. Geotechnical Testing Journal, 31(1): 1-5 (2008).

[13] van Veen A.E. Beheerplan Leendert de Boerspolder. Van landbouwpolder naar waterbergingslocatie (http://www.leendertdeboerspolder.stowa.nl/). 